\title{
Primary Active Epstein-Barr Virus Infection Coexisting With Henoch-Schonlein Purpura in a Child: A Rare Trigger Factor of Henoch-Schonlein Purpura
}

\author{
Sule Gökçe*, Hande Dede, Mehmet Bilal Aracı and Feyza Koç \\ Department of Pediatrics, Ege University, Turkey
}

*Corresponding author: Şule Gökçe, Department of Pediatrics, Ege University Childrens' Hospital, Bornova, Turkey.

\author{
Received Date: July 27, 2018 \\ Published Date: August 21, 2018
}

\begin{abstract}
Henoch-Schonlein purpura (HSP), also known as IgA vasculitis, is the most common vasculitis that effects the small vessels of the skin, joints, gastrointestinal tract, and kidneys in childhood. Epstein barr virus infection is a mild, asymptomatic infection and uncomplicated disease. It is stated that an Epstein-Barr virus infection might be a trigerr factor for Henoch-Schonlein purpura and this togetherness is rarely reported. Herein, we described a patient with Henoch-Schonlein purpura associated with primary active EBV infection. We hope our case report will create awareness of EBV in HSP vasculitis and we suggest that routine serologic investigations may help to detect the possible etiology and/or stimulant factors of HSP.
\end{abstract}

Keywords: Epstein barr virus infection; Henoch-schonlein purpura; Child

\section{Introduction}

Henoch-Schonlein purpura (HSP), also known as IgA vasculitis, is the most common vasculitis that effects the small vessels of the skin, joints, gastrointestinal tract, and kidneys in childhood. It was originally recognised in 1801 by Heberden and described as having an association with arthritis by Schonlein in 1837. The disease is characterized by the triad of palpable purpura, abdominal pain and arthritis. Its etiology is still unknown but clinical, laboratory and epidemiological features suggest transmissible agent or agents.1 It is stated that an Epstein-Barr virus (EBV) infection might cause Henoch-Schonlein purpura and this togetherness is rarely reported. We hope our case report will create awareness of EBV in HSP vasculitis and we suggest that routine serologic investigations may help to detect the possible etiology and/or stimulant factors of HSP.

\section{Case Presentantion}

A previously healthy 5-year-old girl was referred to our clinic with a 4-day history of fever, cough, and nasal discharge. She was treated with clarithromycin for suspected atypical pneumonia. On the 4th day of the treatment, sore throat, swelling in the neck, and a purpuric rash occurred on lower extremities and buttocks. On admission, her temperature was $38.9{ }^{\circ} \mathrm{C}$, heart rate 140 per minute, respiratory rate 24 per minute, and blood pressure was $106 / 76 \mathrm{~mm} \mathrm{Hg}$. Her height was $110 \mathrm{~cm}$ and she weighed $17.8 \mathrm{~kg}$ ( 25-50 and 25 percentiles, respectively). Physical examination at admission revealed several pathological findings such as fever, splenomegaly and left upper cervical lymphadenopathy measured as $3 \times 2 \mathrm{~cm}$. Laboratory investigations at admission included: WBC count $22.600 / \mathrm{mm} 3$ with $65 \%$ reactive lymphocyte and $21 \%$ monocytes, $14 \%$ atypical lymphocytes; hemoglobin $10.5 \mathrm{~g} /$ $\mathrm{dl}$, platelet count $381.000 / \mathrm{mm} 3$; biochemical studies revealed C-reactive protein $4.9 \mathrm{mg} / \mathrm{dL}$ (normal $<0.5 \mathrm{mg} / \mathrm{dL}$ ), serum creatinine of $0.3 \mathrm{mg} / \mathrm{dl}$, blood urea nitrogen of $14 \mathrm{mg} / \mathrm{dl}$, protein $7.7 \mathrm{~g} / \mathrm{dl}$, serum albumin of $4.2 \mathrm{~g} / \mathrm{dl}$, aspartate amino transferase (AST) 23IU/L (<31), alanine aminotransferase (ALT) 13IU/L $(<34)$ and gamma-glutamyltranspeptidase (GGT) 10IU/L (<38). Renal function and urinary analysis were normal. Blood coagulation tests, C3, C4, ANA, other immunoglobulin levels, anti-dsDNA, rheumatoid factor (RF), c-ANCA, p-ANCA and anti streptolysin-O (ASO) were negative. The investigation of Hepatitis $B$ and $C$ serologies, HIV, VDRL-RPR, VZV, CMV, toxoplasma, rubella Ig M and parvovirus antibody were all also negative. The EBV serology tests showed Anti-EA-D Ig G positive, Anti VCA IgM positive, Anti EBNA IgG positive. The throat swab culture and blood culture samples taken 
at the time of admission were negative for infection. Infectious mononucleosis (IM) best known acute clinical manifestation of EBV was suspected due to the child's continuing fever, malaise, specific signs of tonsillitis, and cervical lymph node enlargement. She also had purpuric rashes that were characterized by typical ecchymoses, petechiae, and palpable purpura located primarily on the lower extremities and buttocks (Figure 1). A skin biopsy from the left malleol showed leukocytoclastic vasculitis (Figure 2A \& 2B). In light of these findings, the patient was diagnosed with HSP which was triggered with primary active acute EBV infection and so supportive treatment was given. The clinical findings improved gradually within 15 days.
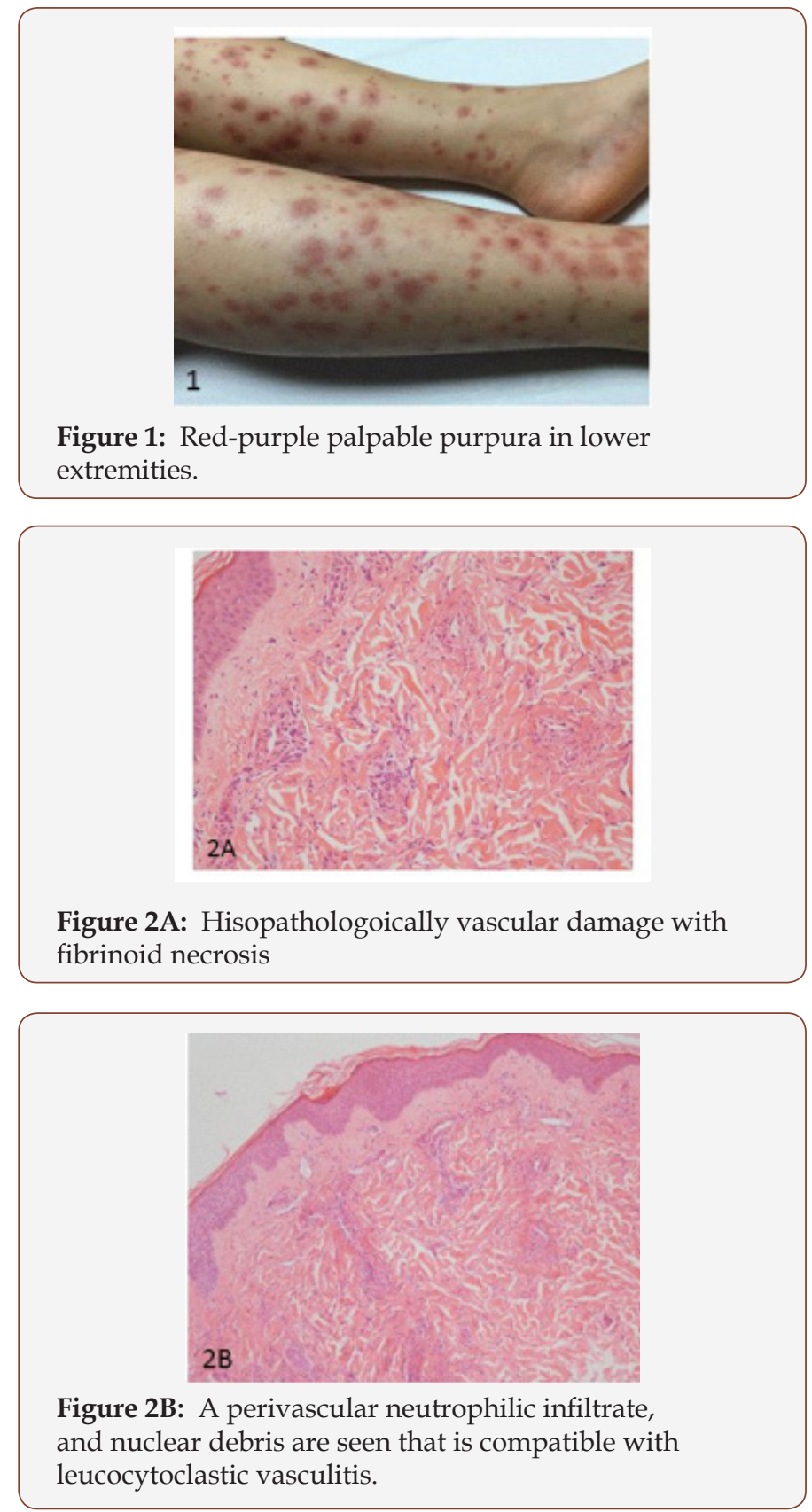

\section{Discussion}

We herein report a case of leukocytoclastic vasculitis diagnosed with primary EBV infection on her initial visit. HenochSchonlein purpura, which is characterized by a triad of non- thrombocytopenic, non-traumatic palpable purpura, abdominal pain and arthritis, is the most common vasculitis in childhood. Immunologic, genetic, and environmental/ethnic factors have been reported to play a role in HSP pathogenesis that is related to the deposition of "immunoglobulin A (IgA)- containing immune complexes" and "complement components" within small vessel walls. However, the etiology is still unknown. Some studies have reported that HSP is associated with infections like Epstein-Barr virus (EBV), streptococcus, varicella, measles, rubella, hepatitis A, B, tuberculosis, mycoplasma, Bartonella, helicobacter pylori, vaccines, foods, and some medications [1-3]. Epstein-Barr virus infection with HSP is seldom entity in childhood. Triggerring of the autoimmun system with EBV is rarely seen and includes a variety of syndromes. The association with many autoimmune diseases of EBV infection suggests that EBV could be a factor that triggers autoimmunity [4]. To our knowledge, Epstein-Barr virus infection has been documented in a few pediatric patients with HSP in the literature. A case study conducted by Guissa VR et al. [5] presented three pediatric patients with chronic acitive Epstein-Barr virus infection which mimicked HSP. Similar to our case, Karakayalı et al. [6] have recently reported a case who was an 8-year old boy admitted to their department with fever, rashes on legs and arms and intermittent mild abdominal pain. His laboratory investigations revealed that monospot test and Anti VCA IgM were positive. The patient was defined as having primary active acute EBV infection associated with HSP vasculitis.

\section{Conclusion}

Primary EBV infection may be assumed to be among the triggers of onset or exacerbation of HSP vasculitis. We hope our case report will create awareness of EBV in HSP vasculitis and we suggest that routine serologic investigations may help to detect the possible etiology and/or stimulant factors of HSP. It should also be considered that EBV infection may be a stimulant factor for autoimmune reactions in the future follow-up of the patients.

\section{Take Home Points}

a. Henoch-Schonlein purpura is the most common vasculitis in childhood.

b. The etiology of Henoch-Schonlein purpura is still unknown; however, the studies have reported that HSP is associated with infections like Epstein-Barr virus (EBV), streptococcus, varicella, measles, rubella, hepatitis A, B, tuberculosis, mycoplasma, Bartonella, helicobacter pylori, vaccines, foods, and some medications.

c. Epstein-Barr virus infection has been documented in a few pediatric patients with HSP in the literature.

d. Epstein-Barr virus infection may be a stimulant factor for autoimmune reactions in the future follow-up of the patients.

\section{Declaration of Conflicting Interests}

The author(s) declared no potential conflicts of interest with respect to the research, authorship, and/or publication of this article. 


\section{References}

1. Yang YH, Yu HH, Chiang BL (2014) The diagnosis and classification of Henoch-Schönlein purpura: an updated review. Autoimmun Rev 13(45): 355-358.

2. Chen O, Zhu XB, Ren P, Wang YB, Sun RP, et al. (2013) Henoch Schonlein Purpura in children: clinical analysis of 120 cases. Afr Health Sci 13(1): 94-99.

3. Rigante D, Castellazzi L, Bosco A, Esposito S (2013) Is there a crossroad between infections, genetics, and Henoch-Schönlein purpura? Autoimmun Rev 12(10): 1016-1021.
4. Nielsen TR, Rostgaard K, Nielsen NM, Koch-Henriksen N, Haahr S, et al. (2007) Multiple sclerosis after infectious mononucleosis. Arch Neurol 64(1): 72-75.

5. Guissa VR, Aragao PA, Marques HH, Jacob CM, Silva CA (2010) Chronic active Epstein-Barr virus infection mimicking Henoch-Schönlein purpura. Acta Reumatol Port 35(5): 513-517.

6. Burcu Karakayalı, Sıla Yılmaz, Deniz Çakır, Pembe Gül Güneş, et al. (2017) Henoch-Schonlein purpura associated with primary active Epstein-Barr virus infection: a case report. Pan African Medical Journal 27: 29. 